\title{
Analysis of Landscape Design and Facilities in National Bank Park at Lahore, Pakistan
}

\author{
Sadia Farooq ${ }^{1}$, Mohammad Arif Kamal ${ }^{2, *}$ \\ ${ }^{1}$ Department of Interior Design, University of Home Economics, Lahore, Pakistan \\ ${ }^{2}$ Architecture Section, Aligarh Muslim University, Aligarh-202002, India
}

Received October 5, 2020; Revised December 29, 2020; Accepted January 20, 2021

\begin{abstract}
Cite This Paper in the following Citation Styles
(a): [1] Sadia Farooq, Mohammad Arif Kamal, "Analysis of Landscape Design and Facilities in National Bank Park at Lahore, Pakistan," Civil Engineering and Architecture, Vol. 9, No. 2, pp. 386-393, 2021. DOI: 10.13189/cea.2021.090211.
\end{abstract}

(b): Sadia Farooq, Mohammad Arif Kamal (2021). Analysis of Landscape Design and Facilities in National Bank Park at Lahore, Pakistan. Civil Engineering and Architecture, 9(2), 386-393. DOI: 10.13189/cea.2021.090211.

Copyright $(2021$ by authors, all rights reserved. Authors agree that this article remains permanently open access under the terms of the Creative Commons Attribution License 4.0 International License

\begin{abstract}
The parks are always required in urban areas but repair is the key feature that enriches parks with the visitors. The maintenance and facilities of the landscape area is a major concern for today's landscapers due to cost analysis and available facilities for the projects. The research worked on the landscape design and facilities provided to the visitors of National Bank Park, Lahore Pakistan. Many research related to landscape have been conducted, but they are not focused on the parks which are constructed under the supervision of a company. The data was collected through a survey and a small interview session from the visitors coming into the park. The balance, proportion, rhythm, and beauty along with a combination of colors, textures, and forms are incorporated in the park. The majority of female students answered the questionnaire, the provided space, gazebos, walking paths, flowering plants, trees and trash bins in the park are satisfactory but cleaning need attention. A floor plan must be provided at the entrance of the park. Interviews concluded that boating area requires frequent water filtration, the swings need to be repaired and food quality and prices need to be evaluated. More trash cans and bins are needed to ensure waste management of the park. The garden needs division of the space to serves different activities.
\end{abstract}

Keywords Landscape Design, Maintenance, Regional Establishments, City Park, Lahore

\section{Introduction}

A landscape can be appealing or not appreciated because of the way the elements, components, and principles are arranged [1]. The landscape area constantly keeps changing because perishable plant's lifespan is short, wooden benches get rotten, iron structures can rust, season changes throughout the year. A skilled landscaper can easily adjust these changes into his design not only to maintain the parks but also to enhance the beauty of the place [2]. Parks are initially important to adjust within the societies for their environmental, ecological, special, and beauty feature [3].

The landscape architecture is a wide field; it includes planning cities, roadsides, backyards of houses, green belts, etc. Landscape features can include anything around us on the earth including the sky. Landscape architecture includes creating areas for meeting the rules and regulations set by environmental agencies and to attract people who are living in that area. It requires proper use of elements through principles of landscape design, including planning, adjustment, maintenance, coverage, and evaluation. The maintenance of the landscape area is a major concern for today's landscapers due to cost analysis and available facilities for the projects [3]. Another major contribution of this field is to design and highlight plus points in coastal areas, industrial zones, and semi-urban areas where fewer expenses and maintenance are the main purpose with landscape designing [4]. Different regions were famous because of their landscape styles like in Chinese gardens unity between rocks, plants, and water 
was crucial. Le Notre, a famous $17^{\text {th }}$ century French designer, stressed a significant principle of symmetry, while Capability Brown, a $18^{\text {th }}$ century English landscaper, used and suggested to incorporate the nature in landscape areas. The client is also influential to change the landscape according to his desires and needs so plants, shrubs, and structures all need to be organized into a pleasing composition of spaces also to satisfy the principles chosen by the designer [3][4][5][6].

The park has to be analyzed on the basis of its design maintenance through its design changes, formal background, plants growth, new plants irrigated, trees topography, etc.

Landscape designing is dependent on climate and microclimates; topography and orientation, site drainage and groundwater recharge; municipal codes; soils and irrigation; human and vehicular access and circulation; recreational amenities; lighting; native plant habitat botany when present; property safety and security; construction detailing and other measurable considerations [6][7]. The study is conducted on National Bank Park, also known as Saint Merry Park. It is a recreational place to enjoy and to spend quality time with family and friends. It is visited by several people on daily bases, some people visit the park in the morning for a regular walk or in the noon and afternoon in winters for sunbath and in evening for recreation and walk in the summers. The park is famous among people living near it because of its greenery and tracks for walking. The park consists of green land with grass including a pond available for boating, a play area for kids, and a food court (Fig. 1, 2).

The statement of the problem is to understand the features of the landscape present in the park and maintenance of the park. The objectives of the study are summarized below:

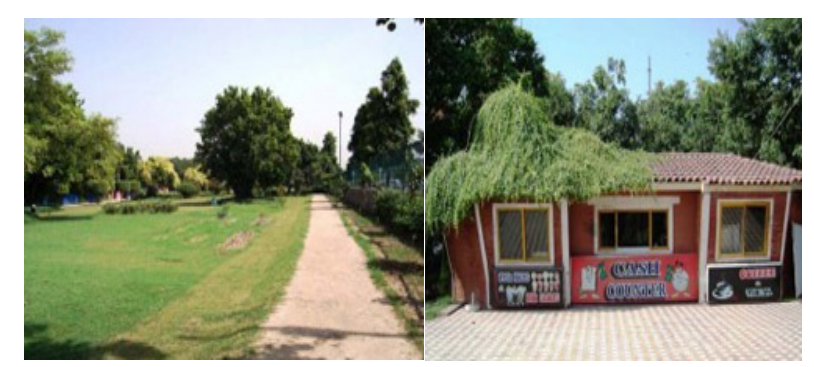

Figure 1. Landscape and Food Court in National Bank Park

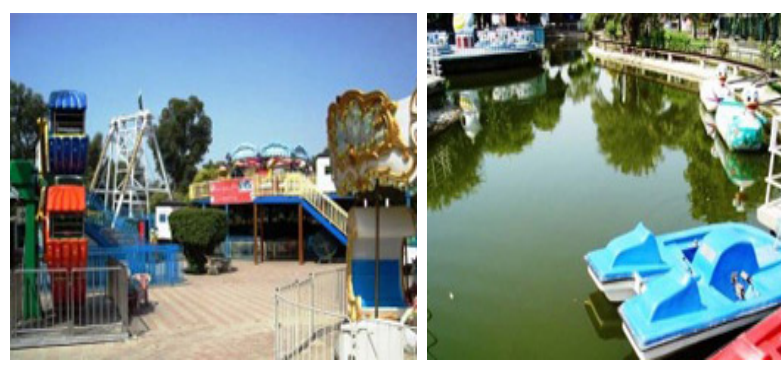

Figure 2. Play and Boating Area in National Bank Park
- To study the landscape design of the park.

- To analyze the condition of softscape and hardscape in the landscape park.

- To analyze the visitor's views about facilities in park.

\section{Literature Review}

With the development of the economy and urbanization process, the urban construction is at an unprecedented speed of development, and various types of urban park cities are around people, which have enriched people's life, improved the natural ecological environment, and enhanced the city's cultural charm. But in the modern urbanization process and under the background of globalization, the city park's landscape has an obvious trend of convergence, and the regional and national characteristics also have gradually disappeared, leading people to produce such an impression: the city parks are the same [3][6]. The regional expression of park landscape characteristics is also an important factor. Since the 90 s, our country city has been developing rapidly, and the urban landscape is changing fast. The parks are serving a number of purposes in cities like providing fresh air, recreation with relaxation, greenery etc. If parks are established on proper landscape principles and elements then they serve as heart touching place after a busy routine. With the development process of the National Bank park and the factors of the regional formation, this report will make some feasible design principles, methods, and strategies through the theoretical summary, case analysis, and method to create city park landscape. We hope for some benefits as the design explores the basis for future park landscape and the related design guidelines. The park design specification of explanation: the park is available for the public to visit, appreciate, rest, and conduct scientific culture and physical exercise activities, with the good facilities and green space [7]. In the above, this paragraph defines the park by a comprehensive definition: the park is for the public as the main function in recreation, with certain recreational facilities and service facilities, beautifying the city, perfecting ecological disaster prevention, and disaster prevention. With the development of the city, the parks also become new, and the ecological parks and its similar one appears, such as industrial landscape parks and ecological parks [4][8]. With the ignoring of the modern socialist initial experience, the traditional value has returned to society, and people more attention to their human cultural value, history protection becomes common sense. Contemporary landscape design combines with modern socialist spirit, the local traditions, and localization. The rich cultural connotation makes the park regional, historic, and belonging, which is easy to be accepted by people and become an indispensable part of park design [3][5][9].

A complete park landscape is the self-maintenance and updated natural garden, and the park always retains a rich 
cultural history. So, it can be said that the park landscape is the most vital landscape, and it is the ideal habitat corridor and the urban green space of the highest quality. The design principles guide designers in organizing elements for a visually pleasing landscape. A harmonious composition can be achieved through the principles of proportion, order, repetition, and unity. All the principles are related and applying one principle helps achieve the others. Physical and psychological comforts are two important concepts in design that are achieved through the use of these principles. People feel more psychologically comfortable in a landscape that has order and repetition. Organized landscapes with predictable patterns (signs of human care) are easier to "read" and tend to make people feel at ease. Psychological comfort is also affected by the sense of pleasure that a viewer perceives from a unified or harmonious landscape. Users feel more physically comfortable, function better, and feel more secure in a landscape with proportions compatible to human scale [3][9][10][11].

\section{Research Methodology}

The research is quantitative and data was collected through a survey from the visitors coming into the park. The purpose of the study was to analyse the landscape design principles in the park, to analyse the condition of soft-scape and hard-scape and visitor's views about facilities in park.

The universe of the study was the small public parks maintained and sponsored by companies so the National Bank Park was chosen as a sample for the study. The questionnaire was filled by 110 visitors who come to the park. The study is limited to park conditions and visitors' views. The following tools were used for the data collection:

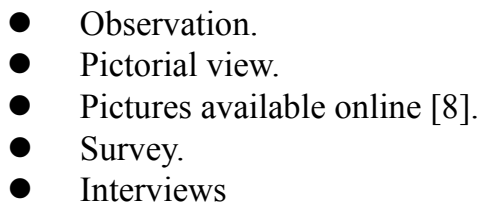

\section{Data Analysis}

\subsection{Analysis of Landscape Design of the Park}

This section is describing the landscape design of the park. The park is situated in Gulberg III, block E2 in Lahore, Punjab, Pakistan. The features present in the park were grass, shrubs, plants, trees, pond along with boating area, play area, and food shops (fig 3).

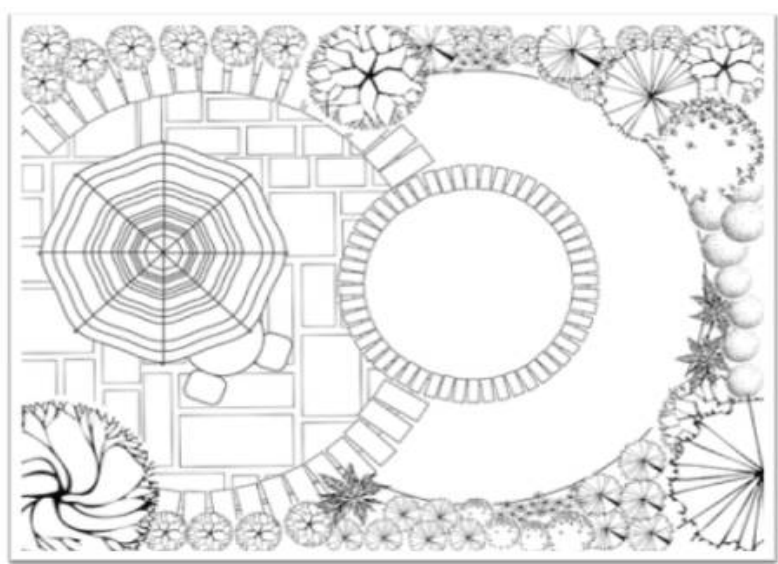

Figure 3. Image showing Division of Areas with Symmetrical Balance in the Park

The analysis of the National Bank Park was concluded on the observations and pictures of the park. The features which were present in the park are described below:

\subsubsection{Proportion in National Bank Park}

The plants were planted in a proportion. The proportion was considered on three elements such as plants, humans, and buildings. Because proportion was according to humans and surroundings so it was well balanced and harmonized. Proportion was also visible in the division of area with grass and plants [3][9][10]. The proportion was also achieved through dividing the park into sitting place, pedestrians and recreational areas.

\subsubsection{Symmetry or Balance in National Bank Park}

The park did not exactly follow the formal symmetrical balance. The small portions were divided in circular cuttings which showed radical balance in the park. Round shaped seedbeds were present in all around the park with same shape and plants (fig 3). Mostly symmetrical balance is found in formal landscape places in which the same objects are placed on either side of an axis. This is also an old traditional concept used in may eras for designing the landscape from an aesthetical point of view [3][9][14].

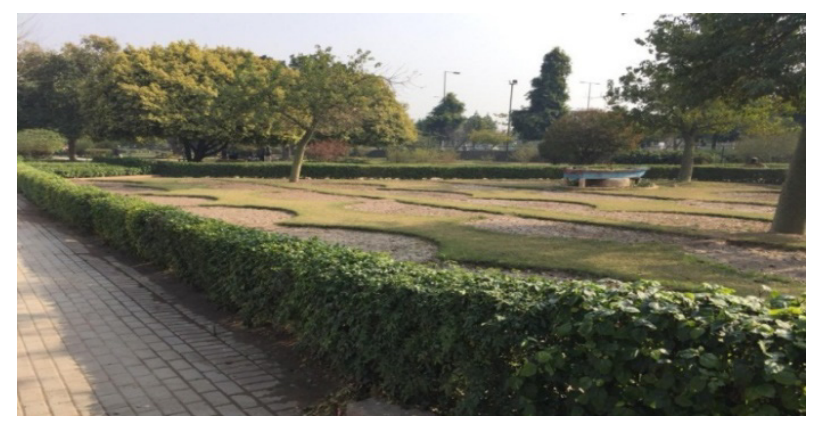

Figure 4. View of the National Bank Park 


\subsubsection{Asymmetrical balance in National Bank Park}

The park has asymmetrical balance in most of the spaces where the height of the trees was balanced to achieve an equal visual weight of nonequivalent forms, color, or texture on either side of an axis, an estimated figure is shown to have an idea of the asymmetrical balance in the park (figure 3 ).

This type of balance is informal and is usually achieved by masses of plants that appear to be the same in visual weight rather than total mass. Figure 4 shows the groupings of trees and solid structures that are approximately equal in visual weight on either side of the axis. The mass can be achieved by combinations of plants, structures, and garden ornaments [3][9][14][15].

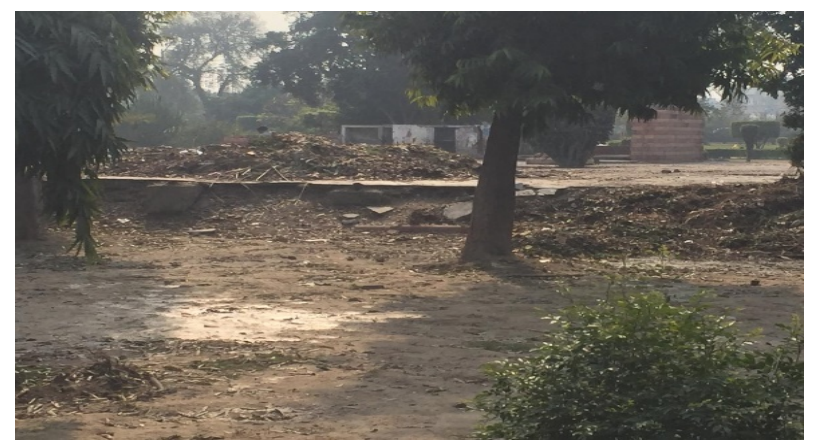

Figure 5. View of Park Showing Poor Maintenance

\subsubsection{Unity in National Bank Park}

The park was united when considering the types and grouping of the plants in the park was considered.

Unity is the linkage of all the elements and principles of landscape design which enhances balance, proportion, rhythm, and beauty. If a park is not organized it will not be appealing to the visitors and lose its attraction to come again.

Unity can also be achieved by combining colors, textures, and forms [3][9][15][16][17].

\subsection{Analysis of Facilities in Park for Visitors}

The survey was conducted to analyse the facilities provided to the visitors in the park.

\subsubsection{Demographic Information}

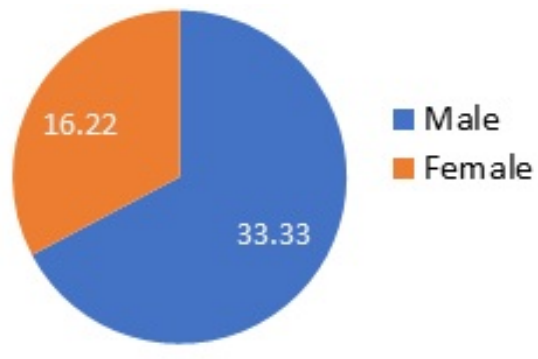

Figure 6. Male and Female Ratio of the Visitors in the Park
Figure 6 shows that 33\% male and 67\% females answered the questionnaire who came to visit the park. So, the majority were female visitors.

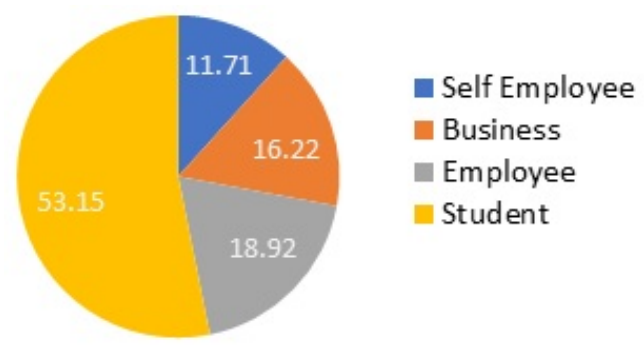

Figure 7. The Visitors' Activities

Figure 7 shows that $53.15 \%$ of visitors are students, $18.92 \%$ employees, $16.22 \%$ involved in business and $11.71 \%$ self-employed. So, most of the visitors were students.

\subsubsection{Facility of Information about Park for Visitors}

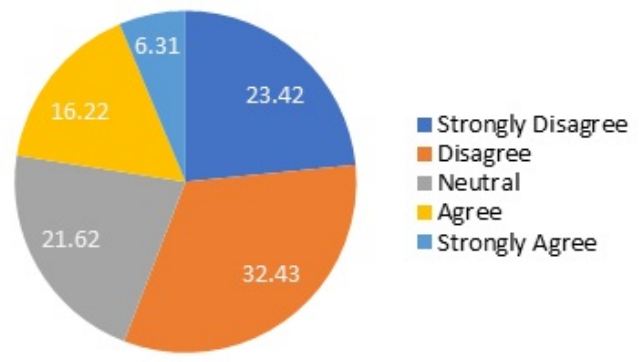

Figure 8. Availability of Floor Plan or Map

Figure 8 shows that $32.43 \%$ visitors disagree, $23.42 \%$ strongly disagree, 21.62 are neutral, $16.22 \%$ agree and $6.31 \%$ strongly agree so most of the visitors disagree on the availability of the park's information in any form like floor plan or map.

\subsubsection{Cleanliness of the Park}

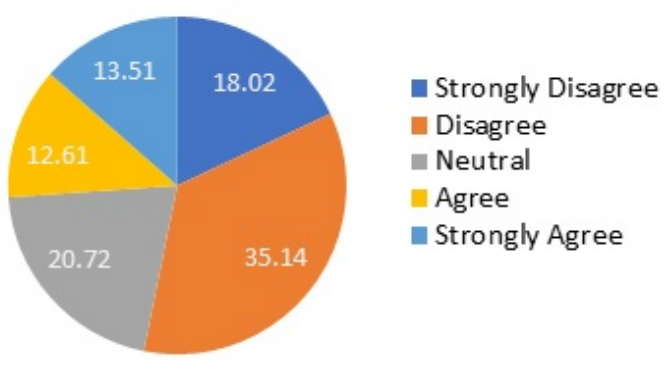

Figure 9. Cleanliness of the Park.

Figure 9 shows that $35.14 \%$ of visitors disagreed, $20.72 \%$ are neutral, $18.02 \%$ strongly disagree, $13.51 \%$ strongly agree and $12.61 \%$ agree that the park is clean enough. So, it is concluded that most of the visitors were not satisfied with the cleaning of the park. 


\subsubsection{Availability of Seats and Tables}

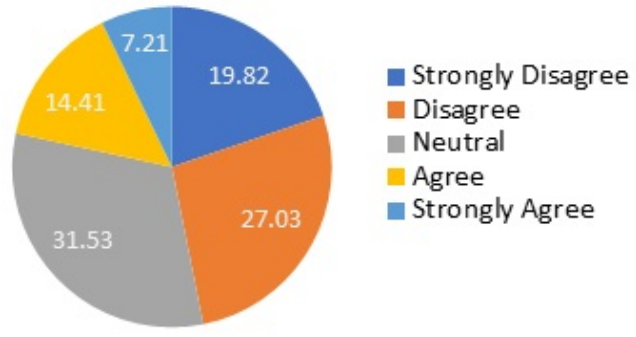

Figure 10. Availability of Seats and Tables

Figure 10 depicts that $31.53 \%$ visitors are neutral, $27.03 \%$ are disagree, $19.82 \%$ are strongly disagree, $14.41 \%$ agree and $7.21 \%$ are strongly agree so it is concluded that most of the visitors were not satisfied with the available quantity of seats and tables.

\subsubsection{Any Damaged Hardscape in the Park}

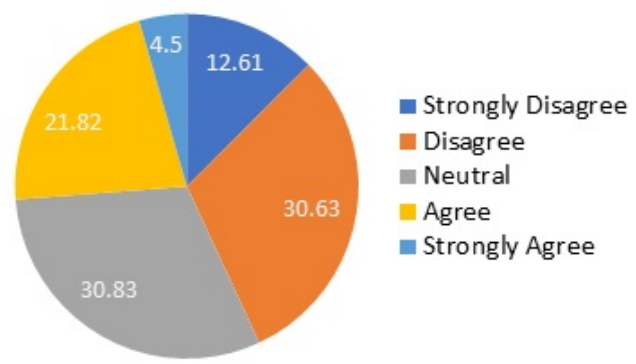

Figure 11. Damaged Hardscape

Figure 11 depicts that $30.83 \%$ people are neutral, $30.63 \%$ disagree, $21.82 \%$ agree, $12.61 \%$ strongly disagree and $4.5 \%$ strongly agree so it is concluded that most of the visitors had not seen damaged hardscape in the park.

\subsubsection{Availability of Trash Bins for Visitors}

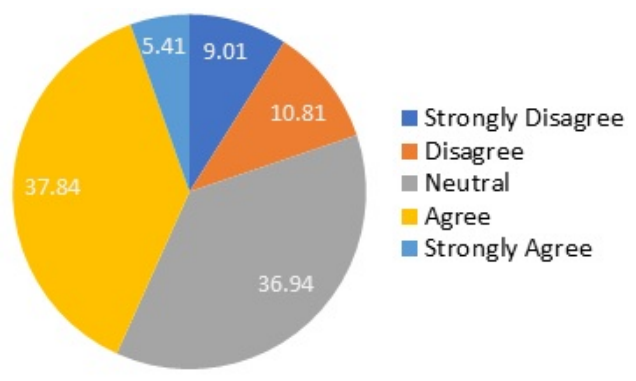

Figure 12. Availability of trash Bins

Figure 12 shows that $37.84 \%$ of visitors are agree, $36.94 \%$ are neutral, $10.81 \%$ are disagree, $9.01 \%$ are strongly disagree and $5.41 \%$ are strongly agree so most of the visitors were satisfied on availability of trash bins.

\subsubsection{Facility of Ample Space for Visitors}

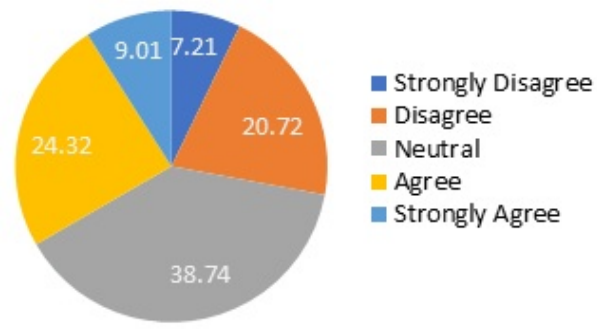

Figure 13. Facility of Ample Space

Figure 13 shows that $38.74 \%$ visitors are neutral, $24.32 \%$ agree, $20.72 \%$ disagree, $9.01 \%$ strongly agree and $7.21 \%$ strongly disagree so most of the visitors agreed in provision of ample space in the park.

\subsubsection{Facility of Shelter/ Gazebo for Visitors}

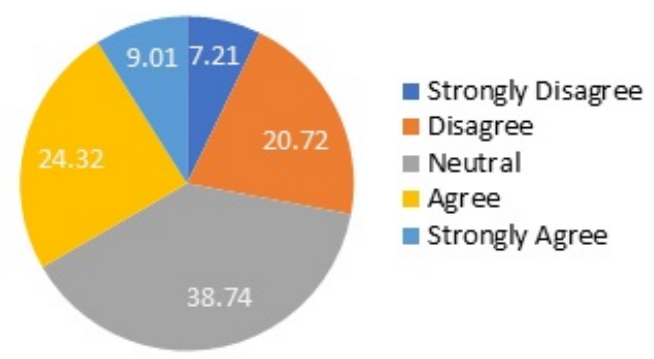

Figure 14. Facility of shelters/ Gazebos

Figure 14 shows that $38.74 \%$ visitors are neutral, $24.32 \%$ agree, $20.72 \%$ disagree, $9.01 \%$ strongly agree and $7.21 \%$ strongly disagree so most of the visitors agreed with the facility of shelter, gazebo in the park.

\subsubsection{Provision of Good Walking Path}

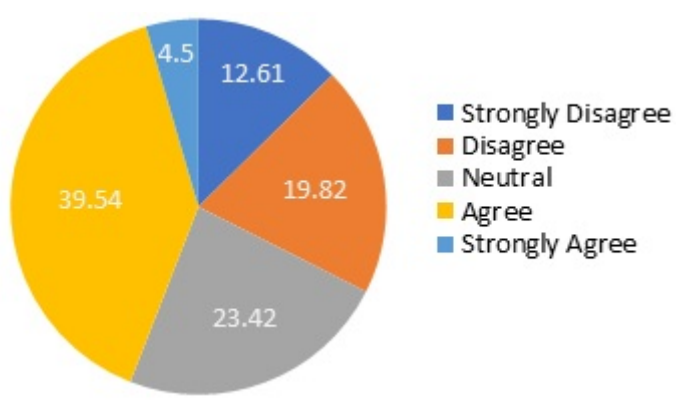

Figure 15. Availability of Good Walk Ways

Figure 15 shows that $39.54 \%$ visitors are agreed, $23.42 \%$ neutral, $19.82 \%$ disagree, $12.61 \%$ strongly disagree and $4.5 \%$ strongly agree so most of the people agreed with the provision of good walking path in the park. 


\subsubsection{Availability of Ample Plants and Trees}

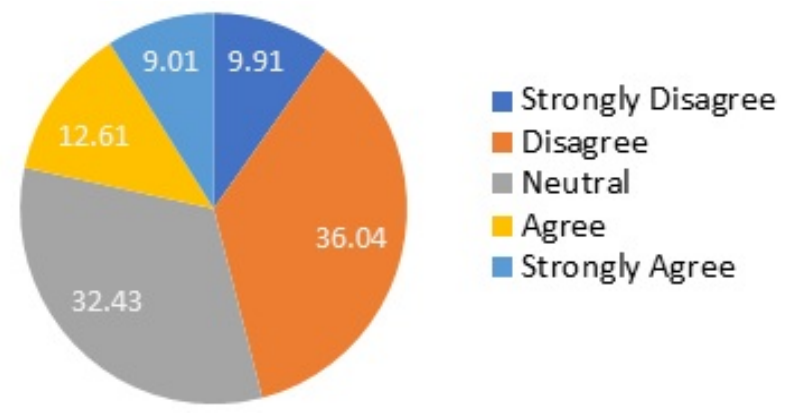

Figure 16. Availability of Ample Plants and Trees.

Figure 16 show that $36.04 \%$ disagree, $32.43 \%$ neutral, $12.61 \%$ agreed, $9.91 \%$ strongly disagreed and $9.01 \%$ strongly agreed so most of the visitors agreed on the availability of ample plants and trees in the park.

\subsubsection{Availability of Ample Flowering Plants}

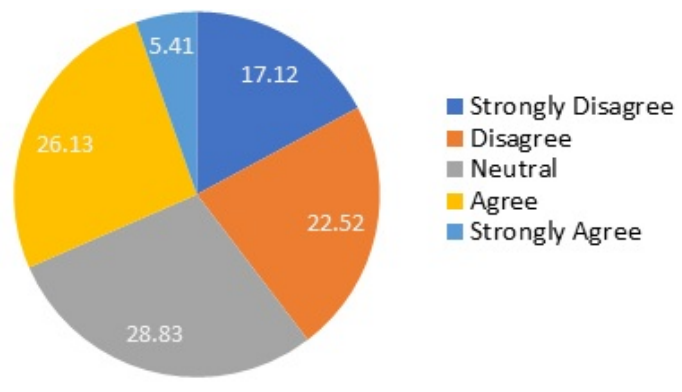

Figure 17. Availability of Ample Flowering Plants

Figure 17 shows that $28.83 \%$ visitors are neutral, $26.13 \%$ agreed, $22.52 \%$ disagree, $17.12 \%$ strongly disagree and $5.41 \%$ strongly agreed so most of the visitors agreed on the availability of ample flowering plants in the park.

\subsubsection{Cleanliness of Refreshing Room}

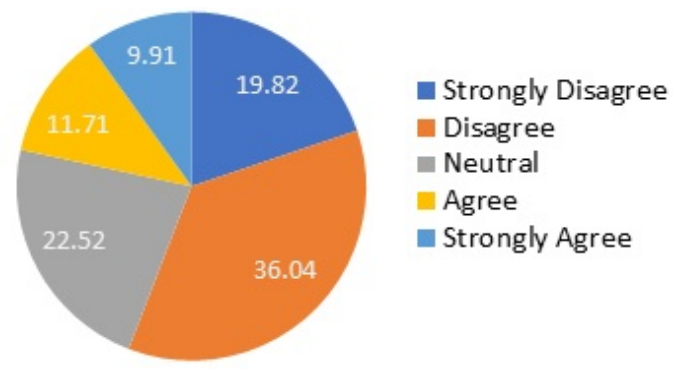

Figure 18. Condition of the Refreshing Room

Figure 18 shows that $36.04 \%$ visitors disagree, $22.52 \%$ neutral, $19.82 \%$ strongly disagree, $11.71 \%$ agreed and $9.91 \%$ strongly agree so most of the visitors disagreed with the cleaning of refreshing room.

4.2.13. Overall Satisfaction of the Visitors in Park

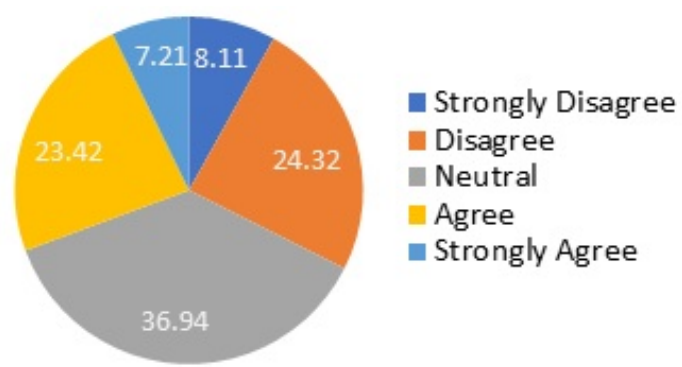

Figure 19. Satisfaction level of the Visitors.

Figure 19 shows that $36.94 \%$ visitors are neutral, $24.32 \%$ disagreed, $23.42 \%$ agreed, $8.11 \%$ strongly disagreed and $7.21 \%$ strongly agreed so most of the visitors were not satisfied with the overall condition of the park.

\subsubsection{I would like to visit the park frequently}

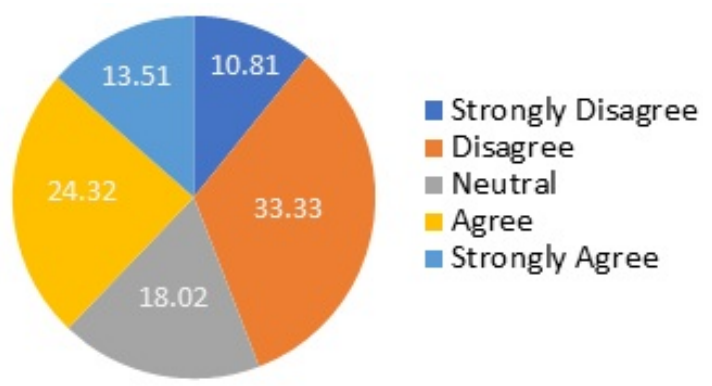

Figure 20. Visitor's thinking about visiting the park Frequently.

Figure 20 shows that $33.33 \%$ disagreed, $24.32 \%$ agreed, $18.02 \%$ neutral, $13.51 \%$ strongly agreed and $10.81 \%$ strongly disagreed so most of the visitors were not willing to visit frequently.

\section{Miscellaneous Facilities}

An interview session was also conducted to add information about recreational facilities and almost 45 visitors were asked about different features, the conclusion of which is given below:

\section{Condition of Boating Area}

The visitors were asked about the condition of boating area in general so they answered that the condition of boats were satisfactory but the water was dirty which needed frequent filtration and cleaning.

\section{Condition of Play Area}

The visitors were asked about play area which was designed for kids so they answered to repair the swings, most of them were damaged; therefore the parents prevented their kids to ride on them. 


\section{Condition of Food Court and Food Quality}

The visitors were asked about the food court and food quality, they were not satisfied with the food quality but they said that furniture was available for them to sit and were also bothered with the high prices.

\section{Summary and Discussion}

The National Bank Park has several features that prove that it a good landscape design. National Bank Park was purposely made for the recreational activities for families. The way the park is designed shows that it has a function of having everything in on a specific area. The park was proportionate with plants, humans, and buildings [3][9][10]. Even the exact symmetrical balance was not present but the tiny portions were having radical balance like around the trees which grow circular because the park was not designed informal layout [3][9][14]. The height of the trees was balanced with each other to achieve an equal visual weight of nonequivalent forms. The color and texture were also not the same in the whole park [3][9][14]. The types and grouping of the plants in the park also give rise to the unity, since unity requires to merge all the elements and principles of landscape design which enhances balance, proportion, rhythm, and beauty along with a combination of colors, textures, and forms [3][9][15][16][17]. The questionnaire was filled by majority of females students which concluded that most of them were not satisfied with the cleaning of the park but most of the hardscape such as seating, tables, gazebos were in good condition.

The visitors want more seats, tables. They were not provided with any information related to park at the entrance in form of floorplan or map. They were satisfied with the provided space, gazebos, walking paths, flowering plants, trees and trash bins in the park but they were not satisfied with the cleaning condition of the refreshing room. Most of the visitors are not satisfied with the overall condition of the park and they do not want to visit frequently. According to a small interview session, the condition of boating area is satisfactory but water filtration is required frequently, the swings in paly area need repair, seating was provided in food court but visitors were not satisfied with the food quality and prices.

\section{Conclusions}

The research was conducted on the park's visitor, who gave an overall idea of the condition of the park and the required working for the park. The conclusion was that the park is providing several basic and recreational facilities but some features need to be rechecked or renovated. The following recommendations are proposed after an analysis of the landscape design and facilities.
- The floor plan or map of garden must be provided at the entrance for visitors' information.

- More sittings features needed in the park.

- Need more trash cans and ensure proper cleaning and waste management of the park.

- Need proper cleaning of the refreshing room.

- Frequent water filtration is required in pool.

- Swings must be repaired for kids' safety.

- Food quality and prices must be rechecked.

\section{REFERENCES}

[1] B. J. Blake. Introduction to landscape design and construction, 1999.

[2] Z. Jia-Xin, Z, T. Hao-Ran, and L. Kun-Fa. Research on Greening Design Based on Urban Landscape. In E3S Web of Conferences, Vol. 165, p. 04036, EDP Sciences, 2020.

[3] S. Farooq. The psychological impact of landscape principles on human beings: A case study of Safari Villas Park Bahria Town, Lahore, Pakistan. Pure and Applied Biology (PAB), Vol. 9, No. 3. Pp. 1820-1830, 2020.

[4] J. 1. Motloch. Introduction to landscape design. John Wiley \& Sons, 2000.

[5] T. D. Glover. Municipal Park and Recreation Agencies unite! A single case analysis of an inter-municipal partnership. Journal of Park and Recreation Administration, Vol. 17, No. 1, 73-90, 1999.

[6] F. D. Malayeri, and N. E. Mastorakis. Urban parks: A new urban landscape architecting scenario.

[7] G. Hansen. Landscape design with edibles. EDIS. Vol. 5, May $31 ; 2013$.

[8] National Bank Park, Pictures Retrieved from http://www.pakistanitourism.com/places-to-go/national-ban k-park on $4^{\text {th }}$ September 2020.

[9] V. Sandeva, K. Despot, and Z. Zlatev. Education influences artistic elements and principles on the street network. International Conference on Virtual Learning. 2018.

[10] D. Fletcher, H. Fletcher. Manageable Predictors of Park Visitor Satisfaction: Maintenance and Personnel. Journal of Park \& Recreation Administration. Vol. 21, No. 1, 2003.

[11] M. L. Cadenasso, and S. T. Pickett. Urban principles for ecological landscape design and maintenance: scientific fundamentals. Cities and the Environment (CATE), Vol. 1, No. 2, pp. 4, 2008.

[12] L. Ribeiro, and T. Barao. Greenways for recreation and maintenance of landscape quality: five case studies in Portugal. Landscape and urban planning, Vol. 76, No. 1-4, pg 79-97. 2006.

[13] M. Liu, and S. Nijhuis. Mapping landscape spaces: Methods for understanding spatial-visual characteristics in landscape design. Environmental Impact Assessment Review, 82, 106376. 2020. 
[14] J. Jakaitis, and J. Zukas. Intuitive spatial interaction in a landscape design environment, Vol. 30, No. 44, pp. 12. 2020.

[15] C. Maller, M. Townsend, L. St Leger, C. Henderson-Wilson, A. Pryor, L. Prosser, and M. Moore. Healthy parks, healthy people: The health benefits of contact with nature in a park context. In The George Wright Forum Vol. 26, No. 2, pp.
51-83, 2009.

[16] E. Gies. The health benefits of parks. The Trust for Public Land, pp. 1-24. 2006.

[17] J. Omoding, G. Walters, s. Carvalho, M. Cracco, C.D. Langoya, K.G. Kiyingi, ... and L. Twinomuhangi. Implementing a Landscape Approach in the Agoro-Agu Region of Uganda. Parks, Vol. 26, pp. 99, 2020. 